Doi: HTTPS://DOI.ORG/10.23910/IJEP/2018.5.3.0256

\title{
First Report of Root Knot (Meloidogyne incognita) on Okra (Abelmoschus esculentus (L) moench) in Dang District of Gujarat
}

\author{
V. P. Prajapati*, Pushpendra Singh and A. J. Deshmukh
}

Dept. of Plant Pathology, College of Agriculture, Navsari Agricutlural University, Waghai (The Dangs) Gujarat (394 730), India

\section{Corresponding Author}

V.P. Prajapati

e-mail: virpathologist@nau.in

\author{
Article History \\ Article ID: IJEP256 \\ Received in $18^{\text {th }}$ June, 2018 \\ Received in revised form $23^{\text {rd }}$ July, 2018 \\ Accepted in final form $17^{\text {th }}$ August, 2018
}

\section{Abstract}

Root knot nematode was heavily infested on okra crop in farmer's field of Kudkas village in Dang district of Gujarat state. Identification of the Meloidogyne incognita is the first occurrence on okra from dang district of Gujarat.

Keywords: Meloidogyne incognita, Root-knot nematode, okra

\section{Introduction}

Okra (Abelmoschus esculentus L. Moench) is one of the most important vegetable crop cultivated throughout India and popular in many tropical and subtropical countries (Singh, 2012). In India, okra is known as "bhindi." India ranks first in the production of okra in the world with $73 \%$ of the total world production of okra (Vanitha et al., 2013.). In Gujarat, the farmers have increasingly started to grow more vegetables in the dang districts. Among all the vegetables, okra is the vegetable with highest production for all the years in Dang district alone having an area of 904ha with the production of 13601MT with 15.05 MT productivity. DHDR (2015). Rootknot nematode, Meloidogyne incognita, is one of the most important pests of vegetable crops, forms knots or galls in infected roots, and causes significant damage. The estimated overall annual yield loss in the world's major crops to damage by plant parasitic nematodes is reported to be $12.37 \%$ (Pankaj and Gaur, 2009) and Root-knot nematode ( $M$. incognita) causes severe damage to okra. (Bhatti and Jain, 1977). The overall losses of vegetables caused by root-knot nematodes have been estimated by $50-80 \%$ (Sasser, 1979). Root-knot nematodes cause severe growth reductions and formation of galls on okra. Sikora and Fernandez (2005).

Heavily infestation of okra root-knot nematode has been observed in the field of Mr. Hanish, a farmer of Kudkas village of Dang district of Gujarat state.Root-knot nematodes are major pests of okra which can cause root galling, wilting, leaf chlorosis, plant growth stunted and reduction of photosynthetic pigments which resulting in yield reduction, reduced shelf-life and poor fruit quality. When plants uprooted, the numerous, small to very big sized galls were observed on tap roots as well as lateral roots ultimately resulted poor development of root system.

Specific identity of the female nematode was determined by the perineal pattern (Goodey, 1963). The galled root system from affected plants was washed in tap water and immersed in a beaker containing boiling $\left(80^{\circ} \mathrm{C}\right) 0.1 \%$ Cotton Blue and left overnight for clearing. Female nematodes were come out from the galls and transferred to a drop of lactophenol taken on a glass slide. The posterior as well as anterior portion of the females was carefully cut with a sharp razor blade and the body contents were cleaned. The perineal pattern of the females was trimmed and mounted for observation as per Taylor et al. (1955). The detail studies for identification of the species were made by comparing characteristics observed in the perineal region and size and shape of root knot nematode with description given by (Singh and Gupta, 2011). Meloidogyne incognita: Female body pear-shaped, without posterior protuberance; Perineal pattern usually with relatively high dorsal arch and without lateral lines; Stylet ranging in length from 15.3 to $17.1 \mathrm{~mm}$, knobs rounded and offset; Male head not offset from the body; Head cap with elevated labial disc, usually without lateral lips, head region often with incomplete head annulations; Second stage juveniles' body 352.5 to $452.2 \mathrm{~mm}$ long; Tail slender, 44.5 to

$66.2 \mathrm{~mm}$ in length, hyaline tail part 7.1 to $15.2 \mathrm{~mm}$ long, anterior regions clearly delimitated, tail-tip rouned. (Singh and Gupta, 2011). Thus, based on the perineal pattern, stylet length, head shape, and juvenile length studies, the said root-knot nematode species were identified as Meloidogyne 


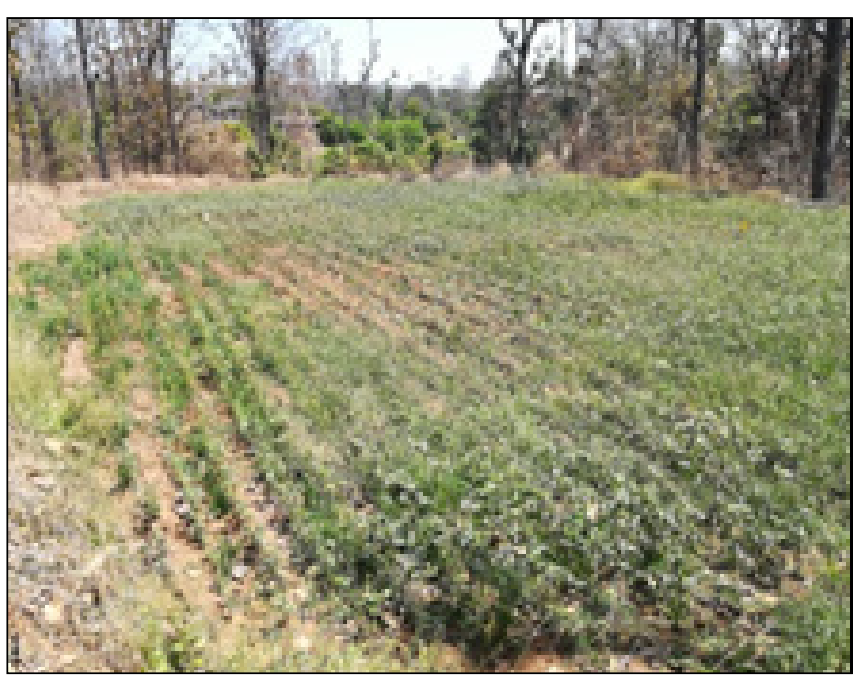

1. Patchy appearance of Okra field infected with root knot nematode

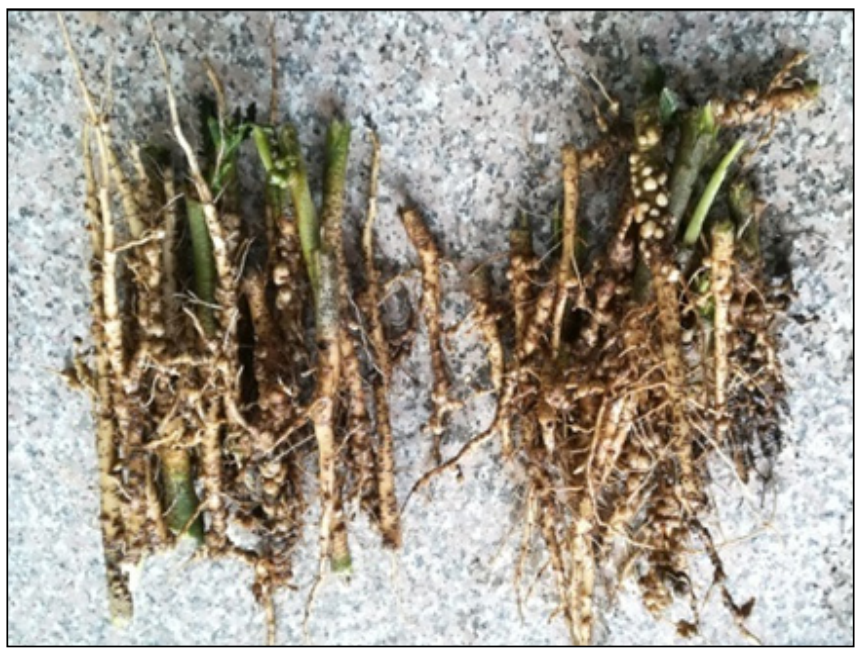

2. Okra Root-knot nematode

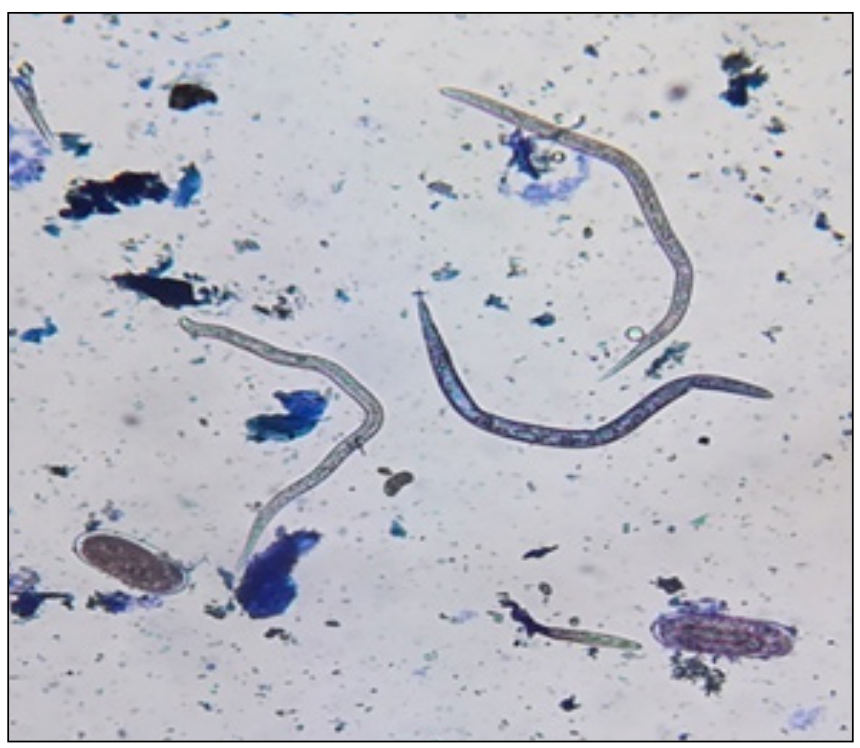

3. Nematode with eggs

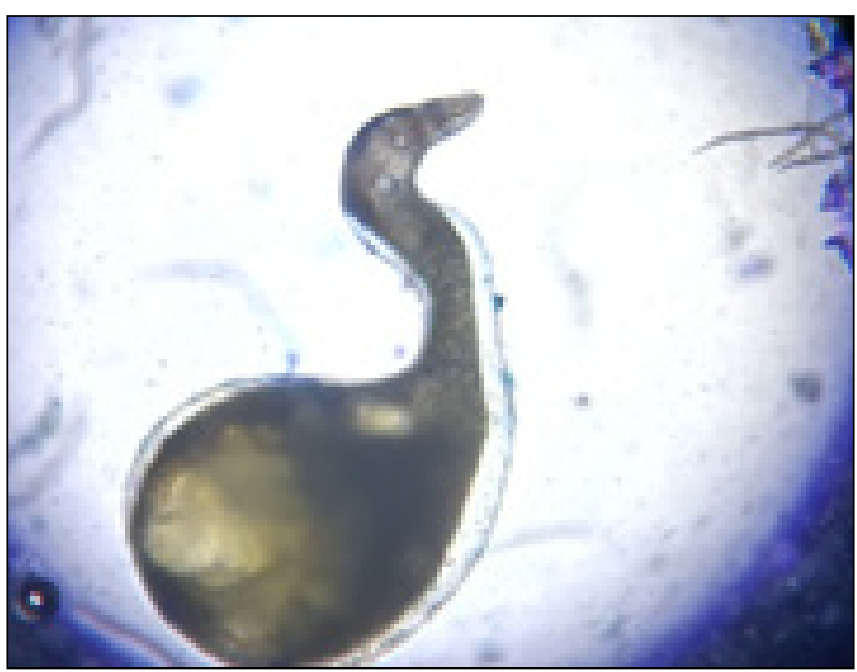

4.1. Mature female

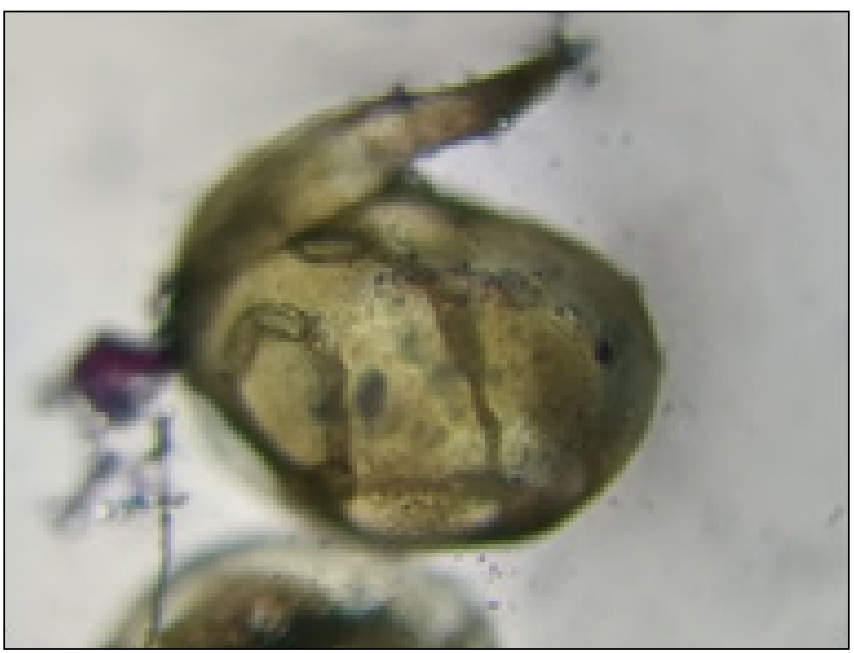

4.2. Mature female

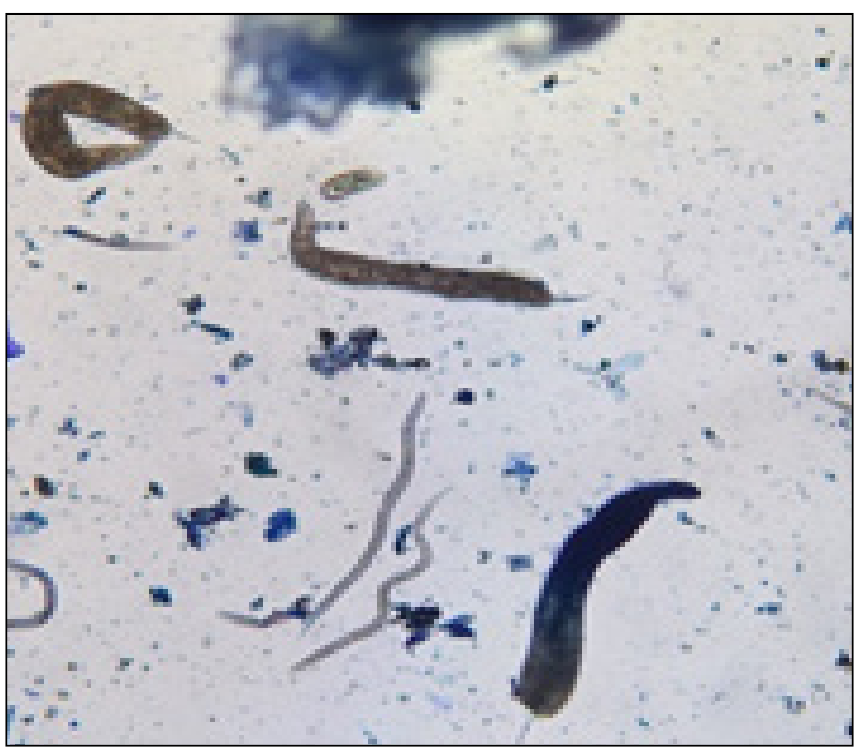

5. Male and Female nematode 
incognita. To our knowledge, this is the first report of $M$. incognita on okra in Dang district of Gujarat state of India.

\section{References}

Bhatti, D.S., Jain, R.K., 1977. Estimation of losses in okra, tomato and brinjal yield due to Meloidogyne incognita. Indian Journal of Nematology 7(1), 37-41.

DHDR, 2015. District human development report:The Dangs. Government of Gujarat, 68.

Goodey, J.B., 1963. Laboratory methods for work with soil and plant nematodes. Technical Bulletin, Ministry of Agriculture, London, 72.

Pankaj \& Gaur, H.S., 2009. Nematodes. In: Handbook of Agriculture. ICAR Publications, New Delhi, 146.

Sasser, J.N., 1979. Economic importance of Meloidogyne in tropical countries. In: Lamberti, F., Taylor, C.E. (Eds.), Root-knot nematodes (Meloidogyne spp): Systematics, Biology and Control. Academic Press, New York,
359-374.

Sikora, R.A., Fernandez, E., 2005. Nematode parasites of vegetables. In: Luc, M., Sikora, R.A., Bridge, J. (Eds.), Plant parasitic nematodes in subtropical and tropical agriculture. CABI Publishing, London, UK, 319-392.

Singh, D., 2012. Genetic control of aluminium tolerance in okra (Abelmoschus esculentus (L.) Moench). Scientia Horticulturae Amsterdam 138, 134-137.

Singh, V.K., Gupta, R.K., 2011. First report of Meloidogyne javanica on ginger and Meloidogyne incognita on coriander in Jammu and Kashmir (India). Journal of Horticultural Science 6(1), 74-75.

Taylor, A.H., Dropkin, V.H., Martin, G.C., 1955. Perineal patterns of root-knot nematodes. Phytopath., 45, 26-34.

Vanitha, S.M., Chaurasia, S.N.S., Singh, P.M., Prakash, S., Naik. 2013. Vegetable Statistics. Technical Bulletin No. 51, IIVR, Varanasi, 1. 